\title{
Continuous low-dose cyclophosphamide and methotrexate combined with celecoxib for patients with advanced cancer
}

\author{
OA Khan', AD Blann', MJ Payne', MR Middleton', AS Protheroe', DC Talbot', M Taylor', C Han', M Patil' \\ and AL Harris*,I
}

'University of Oxford Department of Medical Oncology, Churchill Hospital, Oxford OX3 7LJ, UK; ${ }^{2}$ University Department of Medicine, City Hospital, Birmingham B/8 7QH, UK

\begin{abstract}
BACKGROUND: Combined therapy of metronomic cyclophosphamide, methotrexate and high-dose celecoxib targeting angiogenesis was used in a phase II trial.

METHODS: Patients with advanced cancer received oral cyclophosphamide $50 \mathrm{mg}$ o.d., celecoxib $400 \mathrm{mg}$ b.d. and methotrexate $2.5 \mathrm{mg}$ b.d. for two consecutive days each week. Response was determined every 8 weeks; toxicity was evaluated according to CTC version 2.0. Plasma markers of inflammation, coagulation and angiogenesis were measured.

RESULTS: Sixty-seven of 69 patients were evaluable for response. Twenty-three patients had stable disease (SD) after 8 weeks, but there were no objective responses to therapy. Median time to progression was 57 days. There was a low incidence of toxicities. Among plasma markers, levels of tissue factor were higher in the SD group of patients at baseline, and levels of both angiopoietin- I and matrix metalloproteinase-9 increased in the progressive disease group only. There were no changes in other plasma markers. CONCLUSION: This metronomic approach has negligible activity in advanced cancer albeit with minimal toxicity. Analysis of plasma markers indicates minimal effects on endothelium in this trial. These data for this particular regimen do not support basic tenets of metronomic chemotherapy, such as the ability to overcome resistant tumours by targeting the endothelium.
\end{abstract}

British Journal of Cancer (201I) 104, 1822-1827. doi: 10.1038/bjc.201 I.I54 www.bjcancer.com

Published online 17 May 201I

(c) 20II Cancer Research UK

Keywords: celecoxib; low-dose chemotherapy; angiogenesis

Chemotherapy for the treatment of metastatic cancer mainly follows the rationale that when drugs are effective, higher doses of drugs are even more effective. Unfortunately, this has not produced the anticipated benefits for common solid tumours such as breast cancer (Stadtmauer et al, 2000). A re-evaluation of 'traditional' chemotherapy dose schedules, notably high intermittent doses, has occurred recently following the observation that low doses of chemotherapy given continuously ('metronomic' dosing) can be selectively toxic to proliferating endothelial cells in tumours, which tend to be resistant to standard episodic scheduling (Kerbel and Kamen, 2004). This has an impact on tumour angiogenesis and so tumours resistant to normal bolus doses of chemotherapy may respond to low chronic doses of cytotoxics and with different classes of anti-cancer drugs, such as the combination of low-dose vinblastine chemotherapy and a vascular endothelial growth factor (VEGF) receptor 2 antibody (Klement et al, 2000).

Cyclooxygenase (COX) catalyses reactions needed for the formation of prostaglandins from arachidonic acid. Cyclooxygenase- 1 is constitutively expressed and maintains normal cellular physiological functions such as platelet aggregation and gastric cytoprotection (Needleman et al, 1986). Isoenzyme COX-2 expression is upregulated in inflammation, human tumour

*Correspondence: Professor AL Harris; E-mail: aharris.lab@imm.ox.ac.uk Received 3 December 20 I0; revised 4 April 201 I; accepted 7 April 20II; published online 17 May 20I I neovasculature and in neoplastic cells present in human colon, gastric, breast, prostate, endometrial, skin and lung cancer biopsy tissue (Masferrer et al, 2000; Gately and Kerbel, 2003). There is increasing evidence that COX-2 modulates angiogenesis by augmenting the release of angiogenic peptides such as VEGF, basic fibroblast growth factor (bFGF) and nitric oxide (Gately and Kerbel, 2003). Inhibition of COX-2 by non-steroidal antiinflammatory drugs (NSAIDs) results in reduced angiogenesis and downregulation of proangiogenic factors, such as VEGF and bFGF. Indeed, the incidence of colorectal cancer in patients taking NSAIDs is significantly lower than in those who are not (Dubois et al, 1998). A recent study showed that tumour growth was suppressed by inhibiting angiogenesis with a COX-2 inhibitor both in vitro and in vivo and this was not seen in normal endothelial cells (Muraki et al, 2011). There was also a significant suppression of $\mathrm{CD} 133+/$ vascular endothelial growth factor receptor cells in the circulation by COX-2 inhibition.

Clinically, selective COX-2 inhibition is a more attractive approach due to the lower risk of gastrointestinal toxicity than non-selective NSAIDs. Celecoxib is a selective COX-2 inhibitor (Penning et al, 1997) and is the first COX-2 inhibitor that was given FDA approval and was approved in the UK in 2000, although two trials in patients with adenomatous polyps have been halted prematurely over concerns about its cardiovascular safety (Solomon et al, 2005). A report of the VICTOR study, which was a phase III placebo-controlled trial of rofecoxib in non-metastatic colorectal cancer patients, has demonstrated no effect on overall 
survival (OS) when compared with placebo, but there is a suggestion of a protective effect against recurrence, though this was not statistically significant (Midgley et al, 2010).

Combining low-dose chemotherapy with anti-angiogenic drugs is a rational approach to treating drug-resistant cancers, as it targets both endothelial cells and mechanisms of angiogenesis. Accordingly, we hypothesised that a combination of low-dose chemotherapy with celecoxib could be effective in patients with advanced cancer who were heavily pre-treated with standard chemotherapy and consequently likely to have drug-resistant tumours.

We tested our hypothesis in four different patient groups: breast cancer, gastrointestinal cancer, melanoma and other cancers (ovarian, prostate, renal and unknown primary). The main purpose of the trial was to assess efficacy of the combination in these patients as well as to provide an assessment of safety. Additionally, we evaluated the potential for plasma proteins to act as surrogate angiogenic markers that could be used to monitor treatment activity or be related to achievement of disease stabilisation. These were based on literature reports defining the mechanisms of action in preclinical studies, for example downregulation of anti-angiogenic mechanisms (thrombospondin, TSP) (Lawler, 2002; Bocci et al, 2003), expression of key angiogenic mediators and cytokines (VEGF (Senger et al, 1993), angiopoietins-1 and -2 (ANG-1 and ANG-2) (Davis et al, 1996; Maisonpierre et al, 1997) and interleukin-6 (IL-6)) (Cohen et al, 1996), tissue factor (TF) (Rickles et al, 2003), apoptosis markers (M30) (Gately and Kerbel, 2003) or proteins expressed by endothelial cells (Von Willebrand factor(VWF), soluble E-selectin (sEsel)) (Gehan, 1961; Kerbel and Kamen, 2004) and involved in vascular remodelling (matrix metalloproteinase-9 (MMP-9)) (Bergers et al, 2000).

\section{MATERIALS AND METHODS}

\section{Patient selection}

Adult patients with histologically or cytologically confirmed cancer and evaluable lesions were considered for the study at two clinical centres. Inclusion criteria included WHO performance status (PS) $0-2$ and adequate baseline organ function (absolute neutrophil count $\geqslant 1.5 \times 10^{9}$ per l, platelet count $\geqslant 100 \times 10^{9}$ per l, bilirubin $\leqslant 1.5$ times upper limit of normal, transaminases $<5$ times upper limit of normal and creatinine $\leqslant 150 \mu \mathrm{M}$ ). Patients could not have had radiotherapy, chemotherapy or immunotherapy within the previous 4 weeks (or 6 weeks for nitrosoureas or mitomycin-C). Patients were also excluded if they had active symptomatic disease of the central nervous system, uncontrolled non-malignant disease or a history of gastrointestinal bleeding in the preceding 6 months. A history of allergy to any of the trials drugs was also an exclusion criterion. Patients who had received radiotherapy were included if their assessable disease was outside the radiation field. Written informed consent was obtained from all patients before enrolment. The study was conducted with the approval of the Oxford Research Ethics Committee.

\section{Treatment}

Patients received treatment with cyclophosphamide $50 \mathrm{mg}$ o.d. and celecoxib $400 \mathrm{mg}$ b.d. for 7 days each week, with methotrexate $2.5 \mathrm{mg}$ b.d. for two consecutive days each week. The doses of cytotoxic drugs were selected based on a report of another trial, which utilised the same combination (Colleoni et al, 2002). The dose of celecoxib selected is the standard therapeutic dose. All the drugs were administered PO. Treatment was continued until grade 3 or 4 toxicity and if and when this improved to a grade 2 or better, it was continued with a $25 \%$ reduction in the dose of cyclophosphamide and methotrexate. Treatment was stopped altogether if a further grade 3 toxicity occurred. Treatment was continued until progressive disease (PD), patient refusal of treatment, investigator decision or significant intercurrent illness. Palliative and supportive care for disease-related symptoms was offered to all participants, but the use of aspirin and non-steroidal anti-inflammatory drugs was not permitted under the study protocol.

\section{Evaluations}

Toxicity was graded according to the NCI Common Toxicity Criteria version 2. For grades 1 and 2 events treatment was continued. Dose adjustments were made in the event of grade 3 or 4 toxicities. Treatment was discontinued until the toxicity resolved to grade 2 or better and was then restarted with a $25 \%$ reduction in the doses of cyclophosphamide and methotrexate. If a further grade 3 or 4 toxicity occurred, then treatment was stopped altogether. Delays of over 2 weeks also led to withdrawal from the trial.

Tumour response was assessed according to WHO criteria, with radiological investigations repeated every 8 weeks (Therasse et al, 2000). Time to disease progression was calculated from the date of starting treatment until the date upon which disease progression was first recorded. Stable disease (SD) duration of 3 months was considered a response. Survival was determined from the first day of treatment until the date of death.

\section{Surrogate markers of tumour angiogenesis}

Surrogate markers measured in plasma were MMP-9, VEGF, IL-6, thromospondin (TSP), apoptosis marker (M30), TF, ANG-1, ANG-2, VWF and sEsel (commercial ELISAs, e.g. Dako-Patts, Ely, UK and R\&D Systems, Abingdon, UK). Intra-assay coefficients of variation were $<5 \%$ and inter-assay coefficients were $<10 \%$. Markers were measured in plasma at baseline, after weeks 4 and 8 of therapy.

\section{Statistical methods}

The sample size was selected on the basis that a minimum of 14 patients would ensure that the standard error of the observed response rate was $\leqslant 0.1$ and permit a satisfactory estimate of response rate, but incorporated an early stopping rule according to the method of Gehan (1961), with the response rate of interest set at $20 \%$. This was for each tumour type, but once four main ones were accrued, the study stopped because of slow recruitment in other tumour types. Numbers exceed 14, where 1 or more cases with SD were observed in the in first 14 cases. Descriptive statistics were generated for efficacy, toxicity and pharmacodynamic end points. The median time to progression (TTP) was estimated using Kaplan-Meier survival curves (STATA-1). Angiogenic marker data were subjected to the Anderson-Darling distribution test to direct parametric/non-parametric mode of testing, and is presented as mean and s.d. (when data normally distributed) or median and inter-quartile range (non-normally distributed). The $\chi^{2}$ test was used for categorical data; Spearman's method was used for correlations. Data between groups were analysed by $t$-test or the Mann - Whitney $U$-test. Data at three time points were analysed by Friedman's two-way repeated measures analysis of variance. The log-rank test was used to compare survival between patients with progressive and SD. Significance was assumed if $P<0.05$. All analyses were performed on Minitab release 15 . 


\section{RESULTS}

\section{Patient characteristics}

Seventy-four patients with advanced cancer were enrolled, of whom five patients were not well enough to proceed to treatment. All patients had PD at baseline. Sixty-nine patients completed at least 1 week of celecoxib (median duration that patients received treatment was 10 weeks: range: 1-48 weeks). Fourteen patients were on study for $<8$ weeks, 34 were on study between 8 and 16 weeks, 11 were on study between 16 and 24 weeks and 10 patients were on study for over 24 weeks. The baseline and demographic characteristics for these 69 patients are shown in Table 1. Most patients had a PS of 0 or 1 . The median age was 60 (range: $30-82$ ). The majority of patients had multiple sites of metastatic disease of six different primary origins with the most common disease spread to liver (39\%), lungs (35\%) and bone (17\%). All patients were heavily pre-treated with a median of two previous chemotherapy regimens (range: $1-7$ ) as well as other therapies (Table 1). All 69 patients were assessable for safety. Two patients were excluded from efficacy evaluation with insufficient data. The first of these patients had melanoma and was taken off study on the eighth day. The second of these had prostate cancer and was considered noneligible as he was enrolled in the study without the knowledge that he had life-long asthma, which is an exclusion criterion. He was admitted to hospital with breathlessness and symptoms of a chest infection, the investigators become aware of his asthma and the patient was withdrawn from the study.

\section{Toxicity}

As expected, the incidence of grade 3 or 4 haematological toxicities was low and similarly, other grade 3 or 4 toxicities were rare (Table 2). One patient with renal cell cancer presented with agitation and acute onset confusion after 6 weeks on study. This resolved within $24 \mathrm{~h}$ and CT of the head was normal. He was diagnosed with a transient ischaemic attack.

\section{Dose administration and dose intensity}

Celecoxib dose was maintained for all patients on the trial, in keeping with there being no protocol-defined criterion for its reduction. Methotrexate dose was reduced by $25 \%$ for five patients and cyclophosphamide dose was reduced by $25 \%$ for four patients. There was thus one patient in whom the dose of cyclophosphamide was not reduced as per protocol.

Table I Clinical and demographic details of the patients and details of previous treatments

\begin{tabular}{lc}
\hline Male & 23 \\
Female & 46 \\
Age (range) & $59.5(30.2-82.2)$ \\
Performance status (ECOG) & \\
0 & 19 \\
\hline & 33 \\
2 & 10 \\
Unk & 7 \\
Previous treatment & \\
Surgery & 52 \\
Radiotherapy & 31 \\
Hormonal/biological & 35 \\
Chemotherapy & 50 \\
Prior chemotherapy & \\
Median no prior regimens (range) & $2(1-7)$ \\
\hline
\end{tabular}

Abbreviation: $\mathrm{ECOG}=$ Eastern Cooperative Oncology Group.

\section{Tumour response}

There were no objective responses, but 23 of 67 patients $(34.3 \%)$ evaluable had SD at 12 weeks. The other 44 patients $(65.7 \%)$ progressed. Best response by site of disease is shown in Table 3. The median TTP was 57 days (range: 2 -338). Median OS was 226 days (range: 9-846). The TTP of breast cancer patients was longer than in the other groups (82 days) and the median OS of melanoma patients was shorter than in the other groups (139 days). Survival by response is shown in Figure 1. Patients with SD survived longer than those with $\mathrm{PD}$, although this was not quite statistically significant $(P=0.06)$.

Table 2 Number of patients with grade 3/4 adverse events considered to be related to study treatment

\begin{tabular}{lcc}
\hline Adverse event & Grade $\mathbf{3}$ & Grade 4 \\
\hline Neutropaenia & 1 & 0 \\
Lymphopaenia & 22 & 0 \\
Thrombocytopaenia & 1 & 0 \\
Anaemia & 2 & 1 \\
Fatigue & 1 & 0 \\
Neurological & 6 & 0 \\
Lethargy & 3 & 0 \\
Diarrhoea & 3 & 0 \\
Dyspnoea & 1 & 0 \\
Vomiting & $\mid$ & 1 \\
Malaise & $\mid$ & 0 \\
Indigestion & $\mid$ & 0 \\
Ischaemic attack & $\mid$ & 0 \\
\hline
\end{tabular}

Table 3 Best response per patient and site of disease

\begin{tabular}{lcccc}
\hline Best response site & Not evaluable & PD & SD & Total \\
\hline Breast & 0 & 10 & 5 & 15 \\
Gl & 0 & 10 & 7 & 17 \\
Renal & 0 & 5 & 2 & 7 \\
Melanoma & 1 & 10 & 4 & 15 \\
Ovary & 0 & 1 & 2 & 3 \\
Prostate & 1 & 5 & 3 & 9 \\
Unknown primary & 0 & 3 & 0 & 3 \\
Total & 2 & 44 & 23 & 69 \\
\hline
\end{tabular}

Abbreviations: $\mathrm{Gl}=$ gastrointestinal; $\mathrm{PD}=$ progressive disease; $\mathrm{SD}=$ stable disease.

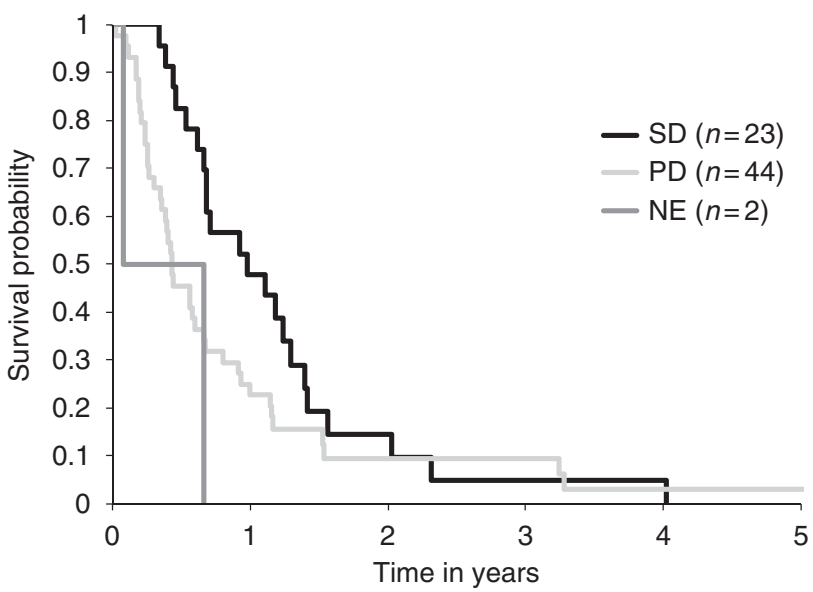

Figure I OS shown by treatment outcome. SD=stable disease; $\mathrm{PD}=$ progressive disease; $\mathrm{NE}=$ non-evaluable. 


\section{Plasma markers}

Results were available for 41 patients (breast cancer: 9, gastrointestinal cancer: 9, renal carcinoma: 2, melanoma: 11, ovarian cancer: 3 and prostate cancer: 7). Samples were only taken from one of the research sites. Table 4 shows changes in the angiogenic markers at the three time points for those in each of the two groups. In cross-sectional analysis, levels of ANG-1 were significantly lower in the $\mathrm{PD}$ group compared with the SD group at baseline. Levels of MMP-9 were higher in the PD group compared with the SD groups at the third time point only. Levels of TF were higher in the SD group at all three time points. In serial analysis, levels of both ANG-1 and MMP-9 increased over the three time points in the PD group only. There were no other statistically significant changes.

\section{DISCUSSION}

This study was designed to assess tumour response to low-dose continuous (metronomic) chemotherapy with high-dose celecoxib in patients with advanced, metastatic cancer and to assess the effects of the combination on surrogate markers of tumour angiogenesis and their relation to disease stabilisation. The combination of cyclophosphamide and methotrexate with celecoxib is based on the postulated importance of angiogenesis in tumour growth, the in vitro and in vivo anti-angiogenic and anti-neoplastic properties of celecoxib and early clinical experience of metronomic

Table 4 Plasma angiogenic marker data

\begin{tabular}{|c|c|c|c|c|}
\hline Marker & $\begin{array}{l}\text { Time } \\
\text { point }\end{array}$ & $\begin{array}{l}\text { Result } \\
\text { (PD) }\end{array}$ & $\begin{array}{l}\text { Result } \\
\text { (s.d.) }\end{array}$ & $\begin{array}{l}P \text { (between } \\
\text { groups) }\end{array}$ \\
\hline \multirow[t]{3}{*}{ ANG-I } & I & $1.0(0.3-6.0)$ & $5.0(1.5-28.0)$ & 0.018 \\
\hline & 2 & $3.0(0.5-6.5)^{*}$ & $4.2(1.2-10.7)$ & 0.297 \\
\hline & 3 & $3.0(0.4-9.0) *$ & $7.0(2.8-34.5)$ & 0.079 \\
\hline \multirow[t]{3}{*}{ ANG-2 } & I & $7.0(4.0-9.7)$ & $7.5(5.0-15.5)$ & 0.264 \\
\hline & 2 & $6.0(4.7-10.0)$ & $13.0(\mid 0.5-18.5)$ & 0.224 \\
\hline & 3 & $7.0(5.2-10.7)$ & $8.0(5.5-18.0)$ & 0.651 \\
\hline \multirow[t]{3}{*}{ IL-6 } & I & $13.0(\mid 0.5-18.5)$ & $19.0(10.0-25.0)$ & 0.194 \\
\hline & 2 & $15.0(10.0-22.5)$ & $15.5(8.5-22.3)$ & 0.947 \\
\hline & 3 & $15.5(5.0-19.5)$ & $15.0(6.5-57.5)$ & 0.995 \\
\hline \multirow[t]{3}{*}{ M30 } & I & $41.0(30.0-175.0)$ & $53.0(30.0-80.0)$ & 0.769 \\
\hline & 2 & $41.0(30.0-147.5)$ & $63.0(30.0-117.0)$ & 0.841 \\
\hline & 3 & $40.0(30.0-140.0)$ & $50.0(30.0-177.0)$ & 0.995 \\
\hline \multirow[t]{3}{*}{ MMP-9 } & । & $60(45-7 \mid)$ & $50(40-62)$ & 0.088 \\
\hline & 2 & $70(56-72)^{*}$ & $60(47-69)$ & 0.095 \\
\hline & 3 & $72(60-74) *$ & $55(43-61)$ & 0.001 \\
\hline \multirow[t]{3}{*}{ sEsel } & I & $92.5(62.5-107.5)$ & $65.0(52.5-132.5)$ & 0.533 \\
\hline & 2 & $92.5(70.0-125.0)$ & $75.0(52.5-115.0)$ & 0.321 \\
\hline & 3 & $90.0(70.0-117.0)$ & $70.0(55.0-92.5)$ & 0.193 \\
\hline \multirow[t]{3}{*}{ TF } & I & $10.0(5.3-87.5)$ & $60.0(21.0-235.0)$ & 0.045 \\
\hline & 2 & $13.0(8.0-79.0)$ & $80.0(41.0-10180)$ & 0.027 \\
\hline & 3 & $19.0(10.0-64.0)$ & $140.0(50.0-10180)$ & 0.012 \\
\hline \multirow[t]{3}{*}{ TSP } & I & $200(4.5-500.0)$ & $60(4.4-300)$ & 0.727 \\
\hline & 2 & $250(6.2-500.0)$ & $50(5.8-287)$ & 0.209 \\
\hline & 3 & $250(112-587)$ & $250(250-400)$ & 0.671 \\
\hline \multirow[t]{3}{*}{ VEGF } & I & $450(125-1900)$ & $500(100-800$ & 0.989 \\
\hline & 2 & $250(113-1450)$ & $320(250-750)$ & 0.378 \\
\hline & 3 & $280(200-4500)$ & $400(130-75000)$ & 0.630 \\
\hline \multirow[t]{3}{*}{ WWF } & I & $115(99-144)$ & $112(103-141)$ & 0.856 \\
\hline & 2 & $120(100-138)$ & $130(103-146)$ & 0.621 \\
\hline & 3 & $112(93-128)$ & $103(84-156)$ & 0.977 \\
\hline
\end{tabular}

Abbreviations: ANG-I = angiopoietin- I; ANG-2 = angiopoietin-2; IL-6 = interleukin-6; MMP-9 = matrix metalloproteinase-9; $\mathrm{PD}=$ progressive disease; $s$ Esel = E-selectin; $\mathrm{TF}=$ tissue factor; TSP = thrombospondin; VEGF = vascular endothelial growth factor; $V W F=$ Von Willebrand factor. 1,2 and 3 refer to visit number. Data presented as median and interquartile range. $P$-value between groups at each time point by the Mann-Whitney U-test. Statistically significantly different $P$-values are in bold. $* P<0.05$ chemotherapy in breast and prostate cancer when standard maximally tolerated dose of chemotherapy has failed. Combination therapy resulted in over 4 month's disease stabilisation in a minority $(34.3 \%)$ of patients and was well tolerated with a low incidence of haematological and non-haematological toxicities. No excess cardiovascular toxicity was observed, although one patient experienced a grade 3 ischaemic attack. Patients were enrolled with high levels of transaminases to include patients with advanced disease, including liver metastases in which a metronomic approach may have been a more suitable option than standard chemotherapy due to lower toxicities. Indeed, there were no significant grades 3 or 4 hepatic toxicities or discontinuations due to hepatic toxicity despite both methotrexate and celecoxib being potentially hepatotoxic drugs.

Clinical experience with metronomic chemotherapy and COX-2 inhibitors is limited, but there have been a number of recent reports suggesting some activity. Colleoni et al (2002, 2006) reported results with low-dose chemotherapy in patients with metastatic breast cancer in two trials. In the earlier trial, clinical benefit rate (CBR: defined as $\mathrm{CR}+\mathrm{PR}+\mathrm{SD}$ for 24 weeks) was $31.7 \%$ and in the second, this was even higher at $41.8 \%$. However, in the first study, the objective response rate (ORR: defined as patients demonstrating complete response or partial response on two separate measurements at least 4 weeks apart) was $19 \%$. Importantly, almost one-fifth of the patients had not received previous treatment for metastatic disease. In the second, the ORR was $16.3 \%$, but almost $40 \%$ of patients had been previously untreated for metastatic disease; in pre-treated patients, the ORR was only $11.8 \%$. In contrast to our study, the PS of patients was mostly 0 or 1 in both these studies. Toxicity was generally mild in both trials.

A phase II trial involving treatment with low-dose oral cyclophosphamide, weekly vinblastine and rofecoxib in 47 patients with advanced solid tumours reported a CBR of $30 \%$ with minimal toxicity (Young et al, 2006). The ORR was only $13 \%$ in a group of mostly good PS patients. Of the responders, three patients had Hodgkin lymphoma and two others had been untreated for metastatic disease.

In a small trial, 35 patients were treated with high-dose celecoxib and low-dose cyclophosphamide in relapsed or refractory non-Hodgkin's lymphoma. The ORR was 37\% (Buckstein et al, 2006). Other clinical studies of these drugs in different cancers have reported varying degrees of success (Needleman et al, 1986; Masferrer et al, 2000; Pasquier et al, 2010; Muraki et al, 2011), although many have not demonstrated significant efficacy (Stempak et al, 2006; Kesari et al, 2007; Steinbild et al, 2007; Stockhammer et al, 2010).

There have been some clinical trials that have reported encouraging results with metronomic chemotherapy combined with other anti-angiogenic drugs. One of these was in breast cancer, where 46 patients with advanced disease were treated with metronomic oral capecitabine and cyclophosphamide plus bevacizumab (Dellapasqua et al, 2008). Objective response rate was $48 \%$ with a CBR of $68 \%$ and mild toxicities. The results of this trial were considered to be of sufficient importance that a phase III trial of this combination is being investigated in Europe. In heavily pre-treated ovarian cancer, 70 patients were treated with oral cyclophospamide and bevacizumab and the ORR was $24 \%$ with a CBR of $56 \%$ (Garcia et al, 2008).

Recently, there have been some reports that have challenged the concept of the anti-angiogenic effects of celecoxib (Xu et al, 2011). The effects of celecoxib in glioma cell lines and xenografts included induction of VEGF expression at a similar level to that induced by hypoxia and formation of new blood vessels in vivo. The authors suggested that cytotoxicity of celecoxib might be due to other effects, such as those on apoptosis rather than on angiogenesis.

Angiogenic therapies often do not induce tumour regression and, therefore, identification and validation of soluble markers of anti-angiogenic activity is essential for successful integration of 
anti-angiogenic therapy into clinical practice. We evaluated changes in soluble markers of angiogenesis in an attempt to correlate changes in these variables with clinical and radiological response. Of these markers, the only significant difference between patients with SD and PD at baseline was ANG-1 and TF, both higher by factors of 5 and 6 , respectively, in those whose disease was stable. Whether this implies a more sensitive vascular bed is not possible to assess. Serial studies showed that levels of MMP-9 increased in line with disease progression, but were stable in those whose disease was stable. In other serial analysis, levels of ANG-1 also increased over the three time points in the PD group only. Surprisingly, levels of other angiogenic cytokines (ANG-2 and VEGF) failed either to differentiate stable from $\mathrm{PD}$, or to be influenced by the treatments. Pre-treatment blood levels of VEGF have been tested in many studies and in general, elevated levels are indicative of poorer prognosis, but do not predict response to anti-angiogenic drugs (Sessa et al, 2008).

Exploratory analysis of outcome by response showed clearly that those with SD had longer survival (Figure 1). As this is a phase II trial, it could be due to intrinsically slower progression of one group of patients, but this could also reflect a difference in the biology and response to therapy, which can only be resolved by randomisation. In all, 7 out of the 10 patients who had long control of disease ( $>24$ weeks) had either breast or colorectal cancer, suggesting that the reason for SD may be due to underlying histology. If those patients who had disease stabilisation for longer than 16 weeks are also included, then 11 out of 21 patients had either breast or colon cancer and a further 2 patients had kidney cancer, all of which are tumour histotypes that may have a more indolent course. Additionally, there was no difference in how heavily pre-treated the patients were when the patients with $\mathrm{SD}$ were compared with those with $\mathrm{PD}$, thus ruling out the possibility that benefit might be greater in less pre-treated patients.

Our data do not support one of the key postulated mechanisms of action of metronomic therapy, that is suppression of TSP, and do not show that VEGF is a good marker for angiogenesis in this setting. A number of other trials using metronomic chemotherapy with or without celecoxib have also reported mixed results when assessing biomarkers of angiogenic activity with most reporting negative findings. For example, in a trial of low-dose metronomic vinblastine and cyclophosphamide with celecoxib for paediatric solid tumours, VEGF, bFGF, sVCAM-1, sICAM-1, endostatin and TSP were measured (Stempak et al, 2006). The results were highly variable and no statistically significant relationship between them and disease progression or maintenance of SD was observed which is likely to be a reflection of small sample size.

In the trial of low-dose chemotherapy in breast cancer conducted by Colleoni et al (2002), there was a significant drop in median VEGF levels comparing baseline to 2 months. There was no difference in median reductions between responders and non-responders, but the reduction was significant only in responders. Overall, the conclusion was that there was no evidence that baseline serum VEGF is associated with predicting response and relative change in serum VEGF from baseline to 2 months was not predictive of response. In a more recent trial in metastatic breast cancer, there was a $30 \%$ reduction in serum VEGF after 2 months in patients with CR or PR and a $14 \%$ reduction in patients with SD. There was no significant reduction in patients with PD (Colleoni et al, 2006). In a phase II trial of metronomic etoposide and cyclophosphamide in combination with daily thalidomide and celecoxib in adults with recurrent malignant gliomas, there was minimal anti-tumour activity and there were no statistically significant differences between responders and non-responders in changes in serum or urine levels of bFGF or VEGF (Kesari et al, 2007).

There is an inconsistent relationship between soluble markers of angiogenesis and response to anti-angiogenic therapy and the practical utility of using drug-induced increases in circulating factors as surrogate biomarkers remains to be demonstrated (Sessa et al, 2008). The lack of normal reference ranges makes it difficult to interpret results. The most specific endothelial markers, VWF and soluble sEsel were, like VEGF and ANG-2, unable to differentiate disease outcome at baseline or response to treatment. However, no changes in these endothelial markers imply lack of damage/dysfunction, suggesting that the therapy is not sufficiently cytotoxic to this organ. In contrast, increased VWF after therapy such as steroids and cisplatin is taken as a reflection of vascular damage (Angles-Cano et al, 1979; Licciardello et al, 1985).

Recently, there has been increasing evidence that tumour endothelial cells may harbour tumour specific genetic abnormalities and, therefore, may acquire drug resistance (Pasquier et al, 2010). Consequently, detailed pharmacogenetic studies on tumour endothelial cells will be needed in future trials of metronomic chemotherapy. There has also been increasing evidence to support additional mechanisms of action of metronomic chemotherapy beyond that of the anti-angiogenic paradigm. These include inhibitory effects on regulatory $\mathrm{T}$ cells leading to an increased anti-tumour immune response, induction of tumour dormancy and direct effects on cancer cells and cancer stem cells (Pasquier et al, 2010).

In conclusion, this combination of daily cyclophosphamide, weekly methotrexate given concurrently with daily celecoxib provided little anticancer activity in a variety of heavily pre-treated patients with advanced solid tumours. The data with this particular combination do not support the basic tenets of metronomic chemotherapy, such as the ability to overcome resistant tumours by targeting the vessels. There has been some evidence recently that disputes the anti-angiogenic effects of COX-2 inhibitors, which might explain why this study among others have seen only minor or no responses with little or no effects on vascular markers of angiogenesis. There may, therefore, be more merit in pursuing combination metronomic therapy trials with drugs with a more established anti-angiogenic mechanism of action.

\section{ACKNOWLEDGEMENTS}

Work at the Churchill Hospital was supported by Cancer Research UK. OAK, ALH and MRM receive support from the NIHR Biomedical Research Centre, Oxford.

\section{REFERENCES}

Angles-Cano E, Sultan Y, Clauvel JP (1979) Predisposing factors to thrombosis in systemic lupus erythematosus: possible relation to endothelial cell damage. J Lab Clin Med 94: 312-323

Bergers G, Brekken R, McMahon G, Vu TH, Itoh T, Tamaki K, Tanzawa K, Thorpe P, Itohara S, Werb Z, Hanahan D (2000) Matrix metalloproteinase- 9 triggers the angiogenic switch during carcinogenesis. Nat Cell Biol 2: $737-744$
Bocci G, Francia G, Man S, Lawler J, Kerbel RS (2003) Thrombospondin 1, a mediator of the antiangiogenic effects of low-dose metronomic chemotherapy. Proc Natl Acad Sci USA 100: 12917-12922

Buckstein R, Kerbel RS, Shaked Y, Nayar R, Foden C, Turner R, Lee CR, Taylor D, Zhang L, Man S, Baruchel S, Stempak D, Bertolini F, Crump M (2006) High-Dose celecoxib and metronomic 'low-dose' cyclophosphamide is an effective and safe therapy in patients with relapsed and 
refractory aggressive histology non-Hodgkin's lymphoma. Clin Cancer Res 12: $5190-5198$

Cohen T, Nahari D, Cerem LW, Neufeld G, Levi BZ (1996) Interleukin 6 induces the expression of vascular endothelial growth factor. J Biol Chem 271: $736-741$

Colleoni M, Orlando L, Sanna G, Rocca A, Maisonneuve P, Peruzzotti G, Ghisini R, Sandri MT, Zorzino L, Nole F, Viale G, Goldhirsch A (2006) Metronomic low-dose oral cyclophosphamide and methotrexate plus or minus thalidomide in metastatic breast cancer: antitumor activity and biological effects. Ann Oncol 17: 232-238

Colleoni M, Rocca A, Sandri MT, Zorzino L, Masci G, Nole F, Peruzzotti G, Robertson C, Orlando L, Cinieri S, de BF, Viale G, Goldhirsch A (2002) Low-dose oral methotrexate and cyclophosphamide in metastatic breast cancer: antitumor activity and correlation with vascular endothelial growth factor levels. Ann Oncol 13: 73-80

Davis S, Aldrich TH, Jones PF, Acheson A, Compton DL, Jain V, Ryan TE, Bruno J, Radziejewski C, Maisonpierre PC, Yancopoulos GD (1996) Isolation of angiopoietin-1, a ligand for the TIE2 receptor, by secretiontrap expression cloning. Cell 87: $1161-1169$

Dellapasqua S, Bertolini F, Bagnardi V, Campagnoli E, Scarano E, Torrisi R, Shaked Y, Mancuso P, Goldhirsch A, Rocca A, Pietri E, Colleoni M (2008) Metronomic cyclophosphamide and capecitabine combined with bevacizumab in advanced breast cancer. J Clin Oncol 26: $4899-4905$

Dubois RN, Abramson SB, Crofford L, Gupta RA, Simon LS, Van De Putte LB, Lipsky PE (1998) Cyclooxygenase in biology and disease. FASEB J 12: $1063-1073$

Garcia AA, Hirte H, Fleming G, Yang D, Tsao-Wei DD, Roman L, Groshen S, Swenson S, Markland F, Gandara D, Scudder S, Morgan R, Chen H, Lenz HJ, Oza AM (2008) Phase II clinical trial of bevacizumab and low-dose metronomic oral cyclophosphamide in recurrent ovarian cancer: a trial of the California, Chicago, and Princess Margaret Hospital phase II consortia. J Clin Oncol 26: 76-82

Gately S, Kerbel R (2003) Therapeutic potential of selective cyclooxygenase2 inhibitors in the management of tumor angiogenesis. Prog Exp Tumor Res 37: $179-192$

Gehan EA (1961) The determination of the number of patients required in a preliminary and a follow-up trial of a new chemotherapeutic agent. J Chronic Dis 13: 346-353

Kerbel RS, Kamen BA (2004) The anti-angiogenic basis of metronomic chemotherapy. Nat Rev Cancer 4: 423-436

Kesari S, Schiff D, Doherty L, Gigas DC, Batchelor TT, Muzikansky A, O'Neill A, Drappatz J, Chen-Plotkin AS, Ramakrishna N, Weiss SE, Levy B, Bradshaw J, Kracher J, Laforme A, Black PM, Folkman J, Kieran M, Wen PY (2007) Phase II study of metronomic chemotherapy for recurrent malignant gliomas in adults. Neuro Oncol 9: 354-363

Klement G, Baruchel S, Rak J, Man S, Clark K, Hicklin DJ, Bohlen P, Kerbel RS (2000) Continuous low-dose therapy with vinblastine and VEGF receptor-2 antibody induces sustained tumor regression without overt toxicity. J Clin Invest 105: R15-R24

Lawler J (2002) Thrombospondin-1 as an endogenous inhibitor of angiogenesis and tumor growth. J Cell Mol Med 6: 1-12

Licciardello JT, Moake JL, Rudy CK, Karp DD, Hong WK (1985) Elevated plasma von Willebrand factor levels and arterial occlusive complications associated with cisplatin-based chemotherapy. Oncology 42: 296-300

Maisonpierre PC, Suri C, Jones PF, Bartunkova S, Wiegand SJ, Radziejewski C, Compton D, McClain J, Aldrich TH, Papadopoulos N, Daly TJ, Davis S, Sato TN, Yancopoulos GD (1997) Angiopoietin-2, a natural antagonist for Tie2 that disrupts in vivo angiogenesis. Science 277: 55-60

Masferrer JL, Leahy KM, Koki AT, Zweifel BS, Settle SL, Woerner BM, Edwards DA, Flickinger AG, Moore RJ, Seibert K (2000) Antiangiogenic and antitumor activities of cyclooxygenase-2 inhibitors. Cancer Res 60: $1306-1311$
Midgley R, McConkey C, Johnstone E, Dunn J, Smith J, Grumett S, Julier P, Iveson C, Yanagisawa Y, Warren B, Langman M, Kerr D (2010) Phase III randomized trial assessing rofecoxib in the adjuvant setting of colorectal cancer: final results of the VICTOR trial. J Clin Oncol 28: 4575-4580

Muraki C, Ohga N, Hida Y, Nishihara H, Kato Y, Tsuchiya K, Matsuda K, Totsuka Y, Shindoh M, Hida K (2011) Cyclooxygenase-2 inhibition causes antiangiogenic effects on tumor endothelial and vascular progenitor cells. Int J Cancer. doi: 10.1002/ijc.25976

Needleman P, Turk J, Jakschik BA, Morrison AR, Lefkowith JB (1986) Arachidonic acid metabolism. Annu Rev Biochem 55: 69-102

Pasquier E, Kavallaris M, Andre N (2010) Metronomic chemotherapy: new rationale for new directions. Nat Rev Clin Oncol 7: 455-465

Penning TD, Talley JJ, Bertenshaw SR, Carter JS, Collins PW, Docter S, Graneto MJ, Lee LF, Malecha JW, Miyashiro JM, Rogers RS, Rogier DJ, Yu SS, Anderson GD, Burton EG, Cogburn JN, Gregory SA, Koboldt CM, Perkins WE, Seibert K, Veenhuizen AW, Zhang YY, Isakson PC (1997) Synthesis and biological evaluation of the 1,5-diarylpyrazole class of cyclooxygenase-2 inhibitors: identification of 4-[5-(4-methylphenyl)-3(trifluoromethyl)-1H-pyrazol-1-yl]benze nesulfonamide (SC-58635, celecoxib). J Med Chem 40: 1347-1365

Rickles FR, Patierno S, Fernandez PM (2003) Tissue factor, thrombin, and cancer. Chest 124: $58 \mathrm{~S}-68 \mathrm{~S}$

Senger DR, Van de Water L, Brown LF, Nagy JA, Yeo KT, Yeo TK, Berse B, Jackman RW, Dvorak AM, Dvorak HF (1993) Vascular permeability factor (VPF, VEGF) in tumor biology. Cancer Metastasis Rev 12: 303-324

Sessa C, Guibal A, Del Conte G, Ruegg C (2008) Biomarkers of angiogenesis for the development of antiangiogenic therapies in oncology: tools or decorations? Nat Clin Pract Oncol 5: 378-391

Solomon SD, McMurray JJ, Pfeffer MA, Wittes J, Fowler R, Finn P, Anderson WF, Zauber A, Hawk E, Bertagnolli M (2005) Cardiovascular risk associated with celecoxib in a clinical trial for colorectal adenoma prevention. $N$ Engl J Med 352: $1071-1080$

Stadtmauer EA, O'Neill A, Goldstein LJ, Crilley PA, Mangan KF, Ingle JN, Brodsky I, Martino S, Lazarus HM, Erban JK, Sickles C, Glick JH (2000) Conventional-dose chemotherapy compared with high-dose chemotherapy plus autologous hematopoietic stem-cell transplantation for metastatic breast cancer. Philadelphia Bone Marrow Transplant Group. $N$ Engl J Med 342: 1069-1076

Steinbild S, Arends J, Medinger M, Haring B, Frost A, Drevs J, Unger C, Strecker R, Hennig J, Mross K (2007) Metronomic antiangiogenic therapy with capecitabine and celecoxib in advanced tumor patientsresults of a phase II study. Onkologie 30: 629-635

Stempak D, Gammon J, Halton J, Moghrabi A, Koren G, Baruchel S (2006) A pilot pharmacokinetic and antiangiogenic biomarker study of celecoxib and low-dose metronomic vinblastine or cyclophosphamide in pediatric recurrent solid tumors. J Pediatr Hematol Oncol 28: $720-728$

Stockhammer F, Misch M, Koch A, Czabanka M, Plotkin M, Blechschmidt C, Tuettenberg J, Vajkoczy P (2010) Continuous low-dose temozolomide and celecoxib in recurrent glioblastoma. J Neurooncol 100: 407-415

Therasse P, Arbuck SG, Eisenhauer EA, Wanders J, Kaplan RS, Rubinstein L, Verweij J, Van Glabbeke M, van Oosterom AT, Christian MC, Gwyther SG (2000) New guidelines to evaluate the response to treatment in solid tumors. European Organization for Research and Treatment of Cancer, National Cancer Institute of the United States, National Cancer Institute of Canada. J Natl Cancer Inst 92: 205-216

$\mathrm{Xu} \mathrm{K}$, Gao H, Shu HK (2011) Celecoxib can induce vascular endothelial growth factor expression and tumor angiogenesis. Mol Cancer Ther 10: $138-147$

Young SD, Whissell M, Noble JC, Cano PO, Lopez PG, Germond CJ (2006) Phase II clinical trial results involving treatment with low-dose daily oral cyclophosphamide, weekly vinblastine, and rofecoxib in patients with advanced solid tumors. Clin Cancer Res 12: $3092-3098$ 